\title{
APPLICATION OF FACTORIAL DESIGNS FOR REDUCING FACTORS IN OPTIMIZATION VIA DISCRETE-EVENT SIMULATION
}

\author{
José Arnaldo Barra Montevechi \\ Renaldo Gonzaga de Almeida Filho \\ André Luiz Medeiros \\ Instituto de Engenharia de Produção e Gestão \\ Universidade Federal de Itajubá \\ Avenida BPS, 1303 - Caixa Postal: 50 \\ Itajubá, MG, 37500-903, BRASIL
}

\begin{abstract}
Optimization via simulation came true; most discrete-event simulation packages have some kind of optimization routines but the optimum search can become very timeconsuming as the factor number increases. This paper objectives show how Factorial Designs help the optimization via simulation to reach the optimum solution by reducing number of factors. A comparative study between an optimization without planning and an optimization planned based on Factorial Designs is carried out. Results are presented where the reduction of the number of runs needed to find the optimum is showed. This work concludes with brief considerations on the Factorial Designs and optimization via simulation integration.
\end{abstract}

\section{INTRODUCTION}

The manufacturing system simulation modeling is dated back to at least the early 1960's (Law and Mccomas 1998) and became one of the most popular and powerful tools employed to analyze complex manufacturing systems (O'Kane 2000; Banks 2005). According to O'Kane (2000), one way to forecast the behavior of these systems is using discrete-event simulation which consists in modeling a system where changes occur at discrete-time intervals. It is appropriated for manufacturing systems as their behavior changes in such way.

Some manufacturing issues addressed by simulation include specifying the need and quantity of equipment and personnel, performance evaluation, and evaluation of operational procedures (Law and Mccomas 1998). The simulation's objectives are classified as performance analysis, capacity/constraint analysis, configuration comparison, optimization, sensitivity analysis and visualization (Harrell et al. 2000).
The optimization via simulation deserves a special attention. Harrell (2000) define optimization as the process of trying different combinations of values for the variables that can be controlled in order to seek the combination of values that provides the most desirable output from the simulation model. However, as the number of variables increases, the optimization phase becomes more timeconsuming. So, planning the variables which will compound the search space is the best choice to be performed before the optimization. To plan the optimization, experiments could be done using factorial designs, for example.

In this paper, a comparative study between an optimization without planning and an optimization planned through Factorial Designs carried out. The objective of this work is to show how Factorial Designs can help the simulation optimization to reach the "best" solution.

To accomplish this objective, a manufacturing cell is modeled and experimental research is done. This methodology is appropriated because of the facility to establish cause and effect relationship (Bryman 1989).

The remainder of this article is organized as follows: Section 2 introduces discrete-event simulation and presents some considerations on performing a simulation. Section 3 introduces optimization via simulation and gives a very brief Genetic Algorithm (GA) description. The considerations on the construction of cell's simulation model are presented at section 4 . The experiments and results analysis are at section 5. The article concludes with some considerations on the integration between Factorial Designs and optimization.

\section{DISCRETE-EVENT SIMULATION}

Simulation is the process of designing a model of a real system and conducting experiments with such a model. This is done with the purpose of understanding the behavior of the system and/or evaluating various strategies for 
the operation of the system (Shannon 1998). Some simulation advantages are:

- One can simulate systems that already exist as well as those that are capable of being brought into existence.

- Simulation allows one to identify bottlenecks in information, material and product flows and to test options for increasing flow rates.

- It allows one to gain insights into how a modeled system actually works and to understand which variables are most important to performance.

- A significant advantage of simulation is its ability to let one experiment with new and unfamiliar situations and to answer "what if" questions.

Some simulation disadvantages are model building requires special training, simulation results can be difficult to interpret, simulation modeling and analysis can be time consuming and expensive, and the misuse of simulation to solve problems when analytical solution is possible or even preferable, and each run of a stochastic simulation model produces only estimates of model's true characteristics for a particular set of input parameters (Law and Kelton 2000, Banks et al. 2005).

In this study, a discrete-event simulation is used which concerns the modeling of a system as it evolves over time by a representation in which the state variables change instantaneously at separate points in time (Law and Kelton 2000). This methodology is ideal to be applied to manufacturing systems because they exhibit discrete production changes (O'Kane et al. 2000).

Some characteristics founded on problems to be analyzed that justified the use of simulation are (Strack 1984, Law and Kelton 2000, O'Kane et al. 2000):

- real-word systems with stochastic elements cannot be accurately described by a mathematical model that can be evaluated analytically;

- it is easier to obtain results from a simulation model than using an analytical method;

- experimentation is impossible or very difficult in a real world system;

- the need of long-period time studies or alternatives that physical models do not provide.

O'Kane et al. (2000) advise following a structured approach when using simulation in manufacturing system studies so that designers can identify within the model, elements of the design which are critical to success. According to these authors, before one begins to apply simulation techniques to manufacturing systems, it is important to be aware of the problems that have to be overcome when attempting to provide solutions to real world situations. These problems comprise tasks as problem and objective definitions through model building, validation and data analysis.

\section{OPTIMIZATION VIA SIMULATION}

Optimization via simulation is the process of trying different combinations of values for variables that can be controlled in order to seek the combination of values that provides the most desirable output from the simulation model (Harrell et al. 2000). According to Fu (2002), the integration between optimization and simulation is recent and has been occurring since the end of the last millennium and the relationship commonly encountered in commercial software is a subservient one where the optimization routine is an add-on to the simulation engine. This optimization routine needs the simulation engine outputs to find the parameter set which leads to the best solution.

There are several techniques for optimization. Some are based on heuristics. According to Silva and Montevechi (2004), the heuristic techniques accomplish good solutions and even finding the optimum solution. However, it is not possible to state that the solutions found by these techniques are the best ones.

\subsection{Genetic Algorithms}

One of the heuristic techniques used in optimization software is the Genetic Algorithms (GA), proposed initially by John Holland in 1975 (Goldberg 1989). The Genetic Algorithms are part of a bigger set called Evolutionary Algorithms (EA). The GA's are very attractive to simulation model optimization because they need neither a formal objective function nor mathematically expressed constrains, but the function result only (Silva and Montevechi 2004).

The main idea behind the GA is the smart exploration of a response surface, where simultaneous searches are performed through specific points from this surface. In a similar way to the Theory of Evolution proposed by Darwin (1936), the GA's manipulate a population of points on the response surface or possible solutions from a proposed problem. This is done in such a way that worse solutions fade away, while the better ones continually evolve in their search for the optimum by exploiting diverse areas simultaneously from the response surface (Tanomaru 1995).

In GA's, each individual or possible solution is defined by a chromosome which is also represented by a codification, usually a binary codification. The number of genes of this chromosome is equal to the number of variables of the proposed problem and the number of bits for each gene is defined according to the precision required. Figure 1 shows a representation of a possible solution (chromosome) for maximization problem of a function $\mathrm{f}(\mathrm{x}, \mathrm{y}, \mathrm{z}, \mathrm{w})$ with four decision variables and six-bit precision, with $\mathrm{f}: \mathfrak{R} \rightarrow \mathfrak{R}$ and search space $\mathrm{S} \subseteq \mathfrak{R}$. 


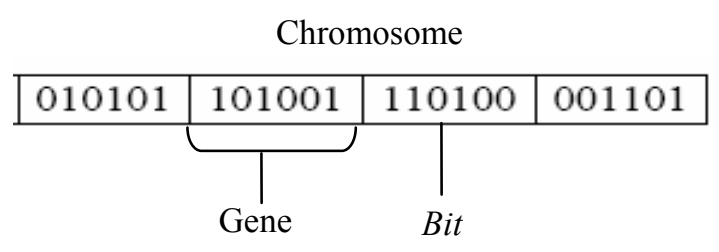

Figure 1: Possible Solution Representation with Four Genes and Six Bits Each. (Source: Silva and Montevechi 2004)

The fitness function defines the fitness or survival chance of each individual in a given population. This function sometimes is the function $\mathrm{f}(\mathrm{x}, \mathrm{y}, \mathrm{z}, \mathrm{w})$ itself. However, there are situations where this function needs to be transformed to better represent the fitness of an individual in the population. Hence, a fitness function for $\mathrm{f}(\mathrm{x}, \mathrm{y}, \mathrm{z}, \mathrm{w})$ could be represented as $\mathrm{G}[\mathrm{f}(\mathrm{x}, \mathrm{y}, \mathrm{z}, \mathrm{w})]$. To evolve the population, the GA's apply genetic operators: selection, cross-over and mutation that have as objective to create new individuals.

The Selection operator offers to the best individuals from population preference to reproduction process, allowing these individuals to pass their characteristics to the next generations. The roulette method is the most utilized method for selection. In this method, $n$ individuals are randomly selected with replacement from a population with $n$ individuals. Then, their fitness values define the probability of them being chosen, as showed by Equation (1).

$$
p\left(c_{i}\right)=\frac{\alpha\left(c_{i}\right)}{\sum_{i=1}^{n} \alpha\left(c_{i}\right)}
$$

where $p\left(c_{i}\right)$ is the probability of the ith individual to be chosen, $\alpha\left(c_{i}\right)$ is the fitness value of the ith individual and $n$ is the number of individuals. At the end, the resultant population has great chance of owning better individuals.

The Cross-over operator creates new individuals combining two or more individuals. The intuitive idea behind this operator is the change of information among different candidate solutions.

The Mutation operator changes randomly an individual characteristic altering a bit value. Hence, the descendant characteristics are limited to ascendant constitution; mutation allows new individuals with characteristics not yet identified to come out (Cunha and Pinto 2001). This change not only assures that the probability of reaching any response surface point is never zero, but it also avoids local optimum.

Cross-over and mutation operators must not be applied to all individuals (Silva and Montevechi 2004). Hence, it is necessary to define the cross-over and mutation rates as well as the size of the population. But, there are not optimum parameters since they are specific for each problem and each codification schema. In addition, they can not be adopted in a generic way as they compromise the global performance of the algorithm (Cunha and Pinto 2001). Other important parameter to be considered is the stop criteria which depends on the problem and the computational effort required and one can adopt the maximum number of generations, the total duration or a minimum value of standard deviation of individual fitness values (Silva and Montevechi 2004).

\section{SYSTEM MODELING}

To accomplish the paper's objective, a manufacturing cell is modeled and it is intended to increase the throughput by adding new equipments. This model is deterministic. It means that no source of randomness is modeled and all input data are constant (Law and Kelton 2000, Banks et al. 2005). The project scope is a manufacturing cell called Group \#1 from pistol slide shop of a defense material supplier.

In order to accomplish a comparison study, it is created an investment scenario, that is, a loan is done to buy new equipments. The loan payment frequency is monthly and this payment is subtracted from monthly profit which is determined by the monthly production multiplied by unitary profit. The problem is to select the optimum set of equipments which profit's increase compensates the additional equipment's purchase cost giving the best return. There are nine simulation model parameters which can be changed. They represent the quantity of equipments that is available to perform a specific task or operation. They assume two values: 1 or 2 . Table 1 presents these parameters.

Table 1: Description of Simulation Model Parameters

\begin{tabular}{|c|l|l|}
\hline \multicolumn{2}{|c|}{ Parameter } & \multicolumn{1}{c|}{ Description } \\
\hline 1 & Neq_Op050 & $\begin{array}{l}\text { Quantity of equipment available to } \\
\text { perform operation 50 }\end{array}$ \\
\hline 3 & Neq_Op052 & $\begin{array}{l}\text { Quantity of equipment available to } \\
\text { perform operation 52 }\end{array}$ \\
\hline 4 & Neq_Op080 & $\begin{array}{l}\text { Quantity of equipment available to } \\
\text { perform operation 70 } \\
\text { perform operation 80 }\end{array}$ \\
\hline 5 & Neq_Op082 & $\begin{array}{l}\text { Quantity of equipment available to } \\
\text { perform operation 82 }\end{array}$ \\
\hline 6 & Neq_Op100 & $\begin{array}{l}\text { Quantity of equipment available to } \\
\text { perform operation 100 }\end{array}$ \\
\hline 7 & Neq_Op110 & $\begin{array}{l}\text { Quantity of equipment available to } \\
\text { perform operation 110 }\end{array}$ \\
\hline 8 & Neq_Op120 & $\begin{array}{l}\text { Quantity of equipment available to } \\
\text { perform operation 120 }\end{array}$ \\
\hline 9 & Neq_Op170 & $\begin{array}{l}\text { Quantity of equipment available to } \\
\text { perform operation 170 }\end{array}$ \\
\hline
\end{tabular}

The optimum set of equipments is determined by two forms. The first form is performing some experiments to 
identify the principal factors and using them as input for the optimization phase. The second one is an optimization using all nine factors.

The following information was obtained on Group \#1: composition (the entities), the amount of workers available (the resources), the activities and their durations, shifts and part routes. Table 2 summarizes this information and Table 3 summarizes the activities of the process..

Table 2: System Element Summary

\begin{tabular}{|l|l|}
\hline Locations & 9 machines \\
\hline Resources & 14 workers distributed at two shifts \\
\hline Processes & 37 activities \\
\hline Controls & $\begin{array}{l}\text { Shifts } \\
\text { Part routes }\end{array}$ \\
\hline
\end{tabular}

Table 3: Process Summary

\begin{tabular}{|l|c|}
\hline Quantity of operations & 9 \\
\hline Quantity of transportations & 19 \\
\hline Quantity of queues & 9 \\
\hline Total & $\mathbf{3 7}$ \\
\hline
\end{tabular}

The Promodel 6.0 simulator was used to build the models. Promodel is a discrete-event simulator for manufacturing and material handle systems.

Model verification and validation were performed by two ways. Initially, a plant expert analyzed whether the behavior of the model would appear reasonable. Then, real historical data was compared with simulated results.

\section{EXPERIMENTATION}

Initially, the experiments are planned to identify the most important factors of the model. Then, these factors are used as input data for optimization software. Also, this model is optimized using all factors as input data in order to compare the results. The optimization software is Simrunner 3.0 which uses Genetic Algorithms and is packaged along with Promodel 6.0.

\subsection{Identifying Important Factors}

According to Law and Kelton (2000), in simulation, experimental designs provides a way to deciding which particular configurations to simulate before the runs are made so the desired information can be obtained with the least amount of simulating. Considering that there are 9 factors, if it were done a full factorial experiment, it would be necessary $2^{9}=512$ runs. Therefore, a screening experiment must be done.

Screening or characterization experiments are experiments in which many factors are considered and the objective is to identify those factors (if any) that have large effects (Montgomery 2001). Typically, screening experiment involves using fractional factorial designs and it is performed in the early stages of the project when many factors are likely considered to have little or no effect on the response (Montgomery 2001). Montgomery (2001) states in this situation it is usually best to keep the number of factors levels low, According to this author, two levels work well. So, the experimental design adopted was a two-level ninefactor fractional factorial with resolution IV. Resolution IV means no main effect is aliased with any others main effect or with any two-factor interaction, but two-factor interactions are aliased with each other (Montgomery 2001). The resolution IV designs available are $2_{I V}^{9-3}=64$ runs and $2_{I V}^{9-4}=32$ runs.

The $2_{I V}^{9-4}$ design was chosen because it has fewer runs than $2_{I V}^{9-3}$ design. If necessary the former design collapses into a five- or less- factor full factorial since preliminary studies have shown that five factors (Op070, Op080, Op082, Op110 and Op120) are critical to cell performance this design works well. The generators for this design are $\mathrm{F}= \pm \mathrm{BCDE}, \mathrm{G}= \pm \mathrm{ACDE}, \mathrm{H}= \pm \mathrm{ABDE}$ and $\mathrm{J}= \pm \mathrm{ABCE}$ and the defining relations are $\mathrm{I}=\mathrm{BCDEF}=\mathrm{ACDEG}=\mathrm{ABDEH}=$ $\mathrm{ABCEJ}=\mathrm{ABFG}=\mathrm{ACFH}=\mathrm{ADFJ}=\mathrm{BCGH}=\mathrm{BDGJ}=$ $\mathrm{CDHJ}=\mathrm{DEFGH}=\mathrm{CEFGJ}=\mathrm{BEFHJ}=\mathrm{AEGHJ}=$ ABCDFGHJ. Table 4 shows the factor assignment to the variables of the design.

Table 4: Variable-Factor Association

\begin{tabular}{|c|c|c|c|}
\hline Variable & Factor & $\begin{array}{c}\text { Low Level } \\
(-)\end{array}$ & $\begin{array}{c}\text { High Level } \\
(+)\end{array}$ \\
\hline A & Neq_Op070 & 1 & 2 \\
\hline B & Neq_Op080 & 1 & 2 \\
\hline C & Neq_Op082 & 1 & 2 \\
\hline D & Neq_Op110 & 1 & 2 \\
\hline E & Neq_Op120 & 1 & 2 \\
\hline F & Neq_Op050 & 1 & 2 \\
\hline G & Neq_Op052 & 1 & 2 \\
\hline H & Neq_Op100 & 1 & 2 \\
\hline J & Neq_Op170 & 1 & 2 \\
\hline
\end{tabular}

Table 5 shows the design matrix for principal fraction with the results obtained for each run. The main factor effects are shown in Figure 2. It is noticed that factors $\mathrm{B}=\mathrm{Neq}$ Op080, $\mathrm{C}=\mathrm{Neq}$ Opp082, E=Neq_Op120 have positive effect. These factors increase the profit when they are increased (high level). The other factors have negative effect that decrease the profit when they are increased (high level). This figure gives a good indication that only three factors must be changed, the other factors must not be changed. However, to have conclusive results, it is necessary to verify the interactions among factors. 


\section{Montevechi, Almeida Filho, and Medeiros}

Table 5: The $2{ }_{I V}^{9-4}$ Design Matrix Principal Fraction and Results

\begin{tabular}{|c|c|c|c|c|c|c|c|c|c|c|}
\hline Run & A & B & C & D & E & F=BCDE & G=ACDE & H=ABDE & J=ABCE & Profit \\
\hline 1 & - & - & - & - & - & + & + & + & + & 280036 \\
\hline 2 & + & - & - & - & - & + & - & - & - & 299418 \\
\hline 3 & - & + & - & - & - & - & + & - & - & 299518 \\
\hline 4 & + & + & - & - & - & - & - & + & + & 280236 \\
\hline 5 & - & - & + & - & - & - & - & + & - & 314818 \\
\hline 6 & + & - & + & - & - & - & + & - & + & 295436 \\
\hline 7 & - & + & + & - & - & + & - & - & + & 315036 \\
\hline 8 & + & + & + & - & - & + & + & + & - & 295654 \\
\hline 9 & - & - & - & + & - & - & - & - & + & 299418 \\
\hline 10 & + & - & - & + & - & - & + & + & - & 280036 \\
\hline 11 & - & + & - & + & - & + & - & + & - & 280136 \\
\hline 12 & + & + & - & + & - & + & + & - & + & 260854 \\
\hline 13 & - & - & + & + & - & + & + & - & - & 295436 \\
\hline 14 & + & - & + & + & - & + & - & + & + & 276054 \\
\hline 15 & - & + & + & + & - & - & + & + & + & 295654 \\
\hline 16 & + & + & + & + & - & - & - & - & - & 315036 \\
\hline 17 & - & - & - & - & + & - & - & - & - & 309109 \\
\hline 18 & + & - & - & - & + & - & + & + & + & 270345 \\
\hline 19 & - & + & - & - & + & + & - & + & + & 270545 \\
\hline 20 & + & + & - & - & + & + & + & - & - & 270445 \\
\hline 21 & - & - & + & - & + & + & + & - & + & 285845 \\
\hline 22 & + & - & + & - & + & + & - & + & - & 285745 \\
\hline 23 & - & + & + & - & + & - & + & + & - & 391945 \\
\hline 24 & + & + & + & - & + & - & - & - & + & 391945 \\
\hline 25 & - & - & - & + & + & + & + & + & - & 270345 \\
\hline 26 & + & - & - & + & + & + & - & - & + & 270345 \\
\hline 27 & - & + & - & + & + & - & + & - & + & 270545 \\
\hline 28 & + & + & - & + & + & - & - & + & - & 270445 \\
\hline 29 & - & - & + & + & + & - & - & + & + & 285945 \\
\hline 30 & + & - & + & + & + & - & + & - & - & 285845 \\
\hline 31 & - & + & + & + & + & + & - & - & - & 398545 \\
\hline 32 & + & + & + & + & + & + & + & + & + & 359781 \\
\hline & & & & & & & & & & \\
\hline
\end{tabular}

The two-factor interactions are shown in Figure 3. It is noticed that the interactions between $\mathrm{BC}=\mathrm{Neq} \_\mathrm{Op} 080$ and Neq_Op082, BE=Neq_Op080 and Neq_Op120, $\mathrm{CE}=\mathrm{Neq} \_\mathrm{Op} 082$ and Neq_Op120 lead to better results, whereas the interactions between $\mathrm{DF}=$ Neq_Op110 and Neq_Op050, GH=Neq_Op052 and Neq_Op100, $\mathrm{AJ}=\mathrm{Neq} \_\mathrm{Op} 070$ and Neq_Op170 lead to poor results.

Taking into consideration interactions $\mathrm{DF}, \mathrm{GH}$ and $\mathrm{AJ}$, it is clear that factors $\mathrm{A}, \mathrm{D}, \mathrm{F}, \mathrm{G}, \mathrm{H}$ and $\mathrm{J}$ must be kept at low level (1) and factors B, C and E must be changed to the high level (2). However, in order to check if it is the best solution, an optimization using these three factors is performed. Following, an optimization using all nine factors is performed to compare their performance.

\subsection{Optimization Using Three Factors}

In this optimization phase, the three factors $\mathrm{B}, \mathrm{C}$ and $\mathrm{E}$ are selected as inputs. The values these parameters can assume are 1 or 2 . The other factors are kept at their original values. The objective function is to maximize the profit as presented earlier in section 4 . After 8 runs, the Simrunner stops the search. The best result found is 411.327 which corresponds to experiment \#6, as presented in Figure 4. The parameter values are presented in Table 6 . 


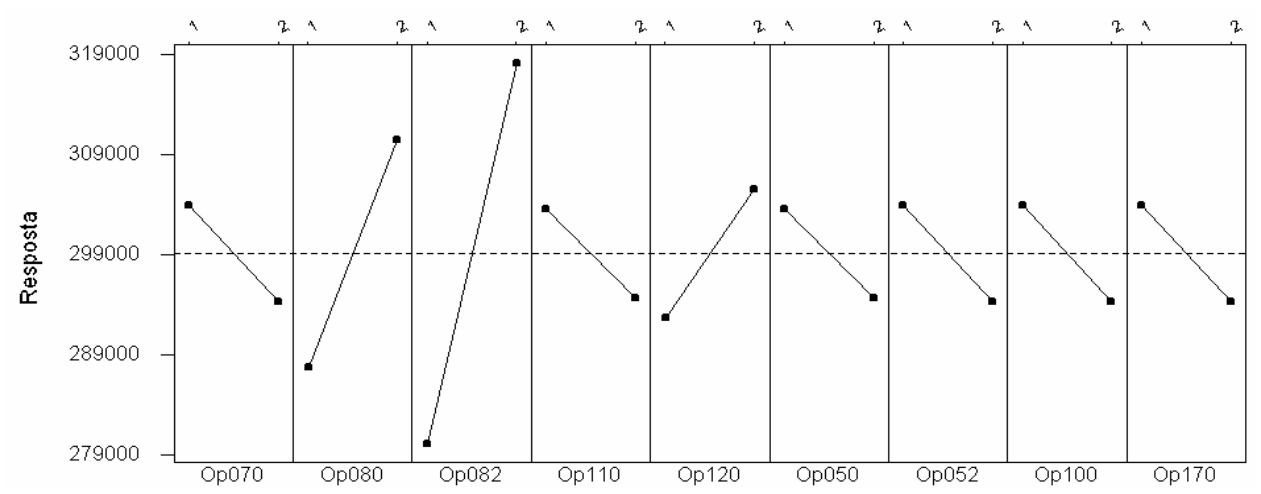

Figure 2: Main Effects Plot for Profit

\begin{tabular}{|c|c|c|c|c|c|c|c|c|c|}
\hline & 1 & 1 & 1 & 1 & 1 & 1 & 1 & 1 & \\
\hline $\begin{aligned} & \text { Op070 } \\
: & 2 \\
: & 1\end{aligned}$ & $20-$ & C & $2=-1$ & $=0$ & $2=--1$ & $2=--1$ & $2=-1$ & $\ldots$ & $\begin{array}{r}-330000 \\
-305000 \\
-280000\end{array}$ \\
\hline & $\begin{aligned} & \text { Op080 } \\
&: 2 \\
&- 1 \\
&\end{aligned}$ & - & $\cdots$ & & $\cdots$ & $\cdots$ & $\cdots$ & $\cdots$ & $\begin{array}{r}-330000 \\
-305000 \\
-280000\end{array}$ \\
\hline & & $\begin{array}{l}\text { Op082 } \\
: 2^{2} \\
1\end{array}$ & $\cdots$ & 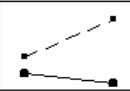 & 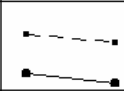 & $\cdots$ & $\cdots$ & $\ldots$ & $\begin{array}{r}-330000 \\
+305000 \\
+280000\end{array}$ \\
\hline & & & $\begin{array}{l}\text { Op110 } \\
: 2 \\
-1\end{array}$ & $x=-$ & $\rightarrow$ & $2=--1$ & $2=--1$ & $2=-=$ & $\begin{array}{r}-330000 \\
+305000 \\
+280000\end{array}$ \\
\hline & & & & $\begin{array}{l}\text { Op120 } \\
: 2 \\
: 1\end{array}$ & $\therefore=$ & 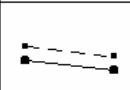 & $=-\infty$ & 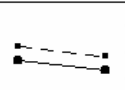 & $\begin{array}{r}-330000 \\
+305000 \\
-280000\end{array}$ \\
\hline & & & & & $\begin{array}{l}\text { Op050 } \\
: 2 \\
-1\end{array}$ & $2=-1$ & $2=-1$ & $2=-1$ & $\begin{array}{r}-330000 \\
+305000 \\
+280000\end{array}$ \\
\hline & & & & & & $\begin{array}{l}\text { Op052 } \\
: 2 \\
-1\end{array}$ & $\rightarrow$ & 2 & $\begin{array}{r}-330000 \\
+305000 \\
+280000\end{array}$ \\
\hline & & & & & & & $\begin{array}{l}\text { Op100 } \\
: 2 \\
-1\end{array}$ & 2 & $\begin{array}{r}-330000 \\
+305000 \\
+280000\end{array}$ \\
\hline & & & & & & & & Op170 & \\
\hline
\end{tabular}

Figure 3: Two-Factor Interaction Plot for Profit

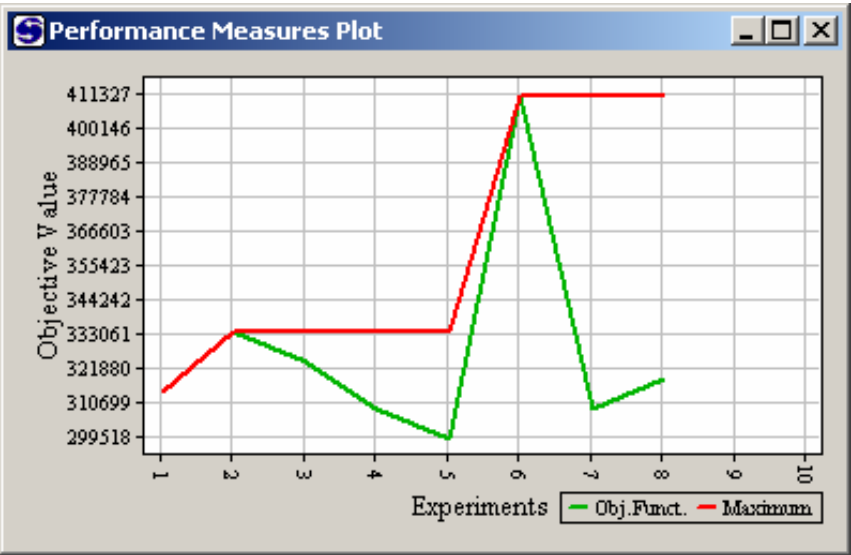

Figure 4: Simrunner's Performance Measures Plot for Optimization Using Three Factors
Table 6: Best Solution for Optimization Using Three Factors

\begin{tabular}{|c|c|}
\hline Parameter & Value \\
\hline Neq_Op080 & 2 \\
\hline Neq_Op082 & 2 \\
\hline Neq_Op120 & 2 \\
\hline
\end{tabular}

\subsection{Optimization Using All Factors}

In this optimization phase, the nine parameters presented in Table 1 are selected as inputs. The values these parameters can assume are 1 or 2 . The objective function is to maximize the profit, as presented earlier in section 4.

After 98 runs, the Simrunner stops the search. The best result found is 411.327 which corresponds to experiment 
\#55 as presented at Figure 5. The parameter values are presented in Table 7.

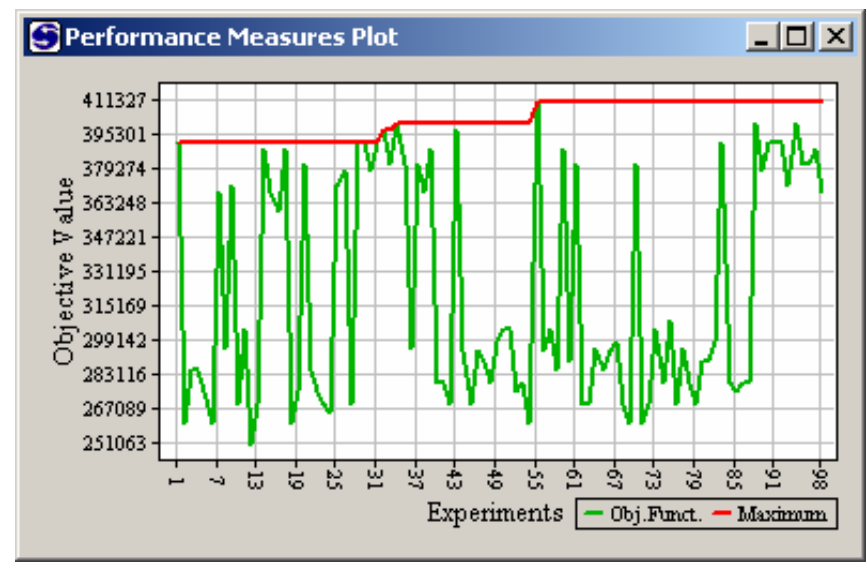

Figure 5: Simrunner's Performance Measures Plot for Optimization Using All Factors

Table 7: Best Solution for Optimization Using All Factors

\begin{tabular}{|c|c|}
\hline Parameter & Value \\
\hline Neq_Op050 & 1 \\
\hline Neq_Op052 & 1 \\
\hline Neq_Op070 & 1 \\
\hline Neq_Op080 & 2 \\
\hline Neq_Op082 & 2 \\
\hline Neq_Op100 & 1 \\
\hline Neq_Op110 & 1 \\
\hline Neq_Op120 & 2 \\
\hline Neq_Op170 & 1 \\
\hline
\end{tabular}

\subsection{Result analysis}

Table 8 shows the results obtained by the three procedures. The three procedures lead to the same results indicating that there is coherency among them. Taking into consideration the number of runs necessary to optimize the model, it is clear the advantage of determining previously the main parameters and then proceeding the optimization using them versus to proceed the optimization using all factors. The former demanded $32+8=40$ runs to obtain the best result against the 98 runs from the latter, a reduction of $59 \%$ in the number of runs. Considering only the runs used in the Factorial Design, 32 runs versus 98 runs from optimization using all factors, the reduction is about $67 \%$.

For this application, since the optimization factor levels and the Factorial Design levels are equal, the optimization using three factors seems meaningless. However, other applications where the optimization factors could have several levels or even were continuous, the Factorial Designs would only identify the main factors without specifying their optimum values.
Table 8: Results from the Three Procedures

\begin{tabular}{|c|c|c|c|}
\hline Parameter & $\begin{array}{c}\text { Factorial } \\
\text { Design }\end{array}$ & $\begin{array}{c}\text { Optimization } \\
\text { using 3 fac- } \\
\text { tors }\end{array}$ & $\begin{array}{c}\text { Optimization } \\
\text { using all fac- } \\
\text { tors }\end{array}$ \\
\hline Neq_Op050 & 1 & $1\left(^{*}\right)$ & 1 \\
\hline Neq_Op052 & 1 & $1\left(^{*}\right)$ & 1 \\
\hline Neq_Op070 & 1 & $1\left(^{*}\right)$ & 1 \\
\hline Neq_Op080 & 2 & 2 & 2 \\
\hline Neq_Op082 & 2 & 2 & 2 \\
\hline Neq_Op100 & 1 & $1\left(^{*}\right)$ & 1 \\
\hline Neq_Op110 & 1 & $1\left(^{*}\right)$ & 1 \\
\hline Neq_Op120 & 2 & 2 & 2 \\
\hline \begin{tabular}{c} 
Neq_Op170 \\
\hline $\begin{array}{c}\text { Result } \\
\text { (profit) }\end{array}$
\end{tabular} & 1 & $1\left(^{*}\right)$ & 1 \\
\hline $\begin{array}{c}\text { Number of } \\
\text { runs }\end{array}$ & $\mathbf{3 2}$ & $\mathbf{8}$ & $\mathbf{4 1 1 3 2 7}$ \\
\hline
\end{tabular}

The parameters identified with $(*)$ were not used as input for optimization. They were kept at low level (1).

\section{CONCLUSIONS}

The objective of this work was to show how the Factorial Designs can help the simulation optimization to reach the "best" solution. First, the more relevant model's factors were identified using Factorial Designs. Afterwards, two optimization were carried out: one using the factors previously identified, and the other using all model's factors.

For this application, the solutions obtained from optimization were the same but the numbers of runs were significantly different. The Factorial Designs reduced up to $59 \%$ of the numbers of runs needed to find the optimum solution. As the optimization factor levels and the Factorial Design levels were equal, the optimization phase was unnecessary and the runs reduction went up to $67 \%$.

For complex system simulation, where the simulation itself is very time-consuming, the Factorial Designs make possible some special approaches as regression metamodels and response surface methodology (Kleijnen 1998) which are recommendations for future works.

\section{ACKNOWLEDGMENTS}

The authors acknowledge CAPES (Project 023/05) and FAPEMIG to support this research.

\section{REFERENCES}

Banks, J., J. S. Carson, B. L. Nelson, and D. M. Nicol. 2005. Discrete-event system simulation. $4^{\text {th }}$ ed. New Jersey: Prentice Hall. 608 p. ISBN 0-13-144679-7. 
Bryman, A. 1989. Experimental Research. Research methods and organization studies, Cap. 3, 71-103. London: Unwin Hyman. ISBN 0-415-08404-0.

Cunha, A. S., R. L. U. F. Pinto. 2001. Uma técnica para ajuste dos parâmetros de um Algoritmo Genético. In Anais do XXXIII Simpósio Brasileiro de Pesquisa Operacional. Campos do Jordão, São Paulo: SBPO. CD-ROM.

Darwin, C. 1936. The origin of species by means of natural selection. New York: The Modern Library. 1000 p.

Fu, M. C. 2002. Optimization for simulation: theory vs. practice. INFORMS Journal on Computing, v. 14, n. 3, p. 192-215, Summer.

Goldberg, D. E. 1989. Genetic algorithms in search, optimization and machine learning. Addison-Wesley Publishing Company. 432p. ISBN 0201157675.

Harrell, C., B. K. Ghosh, R. Bowden. 2000. Simulation Using ProModel, $3^{\text {rd }}$ ed. Boston: McGraw-Hill. 603 p. ISBN 0-07-234144-0.

Kleijnen, J. P. C. 1998. Experimental design for sensitivity analysis, optimization, and validation of simulation models. In Handbook of Simulation, ed. J. Banks, cap. 6, 173-223. New York: John Wiley \& Sons. ISBN 0471-13403-1.

Law, A. M., W. D. Kelton. 2000. Simulation modeling and analysis. $3^{\text {rd }}$ ed. New York: McGraw-Hill. 760 p. ISBN 0-07-059292-6.

Law, A. M., M. G. McComas. 1998. Simulation of manufacturing systems. In Proceedings of the 1998 Winter Simulation Conference, ed. D. J. Medeiros, E. F. Watson, M. S. Manivannan, 49-52. Piscataway, New Jersey: Institute of Electrical and Electronics Engineers. Available via <http: / / www. informs-sim.org /wsc98papers/007.PDF> [accessed March 30, 2006].

Montgomery, D. C. 2001. Design and analysis of experiments. $5^{\text {th }}$ ed. New York: John Wiley \& Sons. 684 p. ISBN 0-471-31649-0.

O’Kane, J. F., J. R. Spenceley, R. Taylor. 2000. Simulation as an essential tool for advanced manufacturing technology problems. Journal of Materials Processing Technology v.107, p.412-424.

Shannon, R. E. 1998. Introduction to the art and science of simulation. In Proceedings of the 1998 Winter Simulation Conference, ed. D. J. Medeiros, E. F. Watson, M. S. Manivannan, 7-14. Piscataway, New Jersey: Insti- tute of Electrical and Electronics Engineers. Available via <http://www.informs-sim.org/wsc98 papers/001. PDF> [accessed March 30, 2006].

Silva, W. A., J. A. B. Montevechi. 2004. Verificação do custeio de uma célula de manufatura usando simulação e otimização. In Anais do XXXVI Simpósio Brasileiro de Pesquisa Operacional. São João Del Rei, Minas Gerais:SBPO. CD-ROM.

Strack, J. 1984. GPSS: modelagem e simulação de sistemas. Rio de Janeiro: LTC.

Tanomaru, J. 1995. Motivação, fundamentos e aplicações de algoritmos genéticos. In Anais do II Congresso Brasileiro de Redes Neurais. Curitiba, Paraná.

\section{AUTHOR BIOGRAPHIES}

JOSÉ ARNALDO BARRA MONTEVECHI is a Titular Professor of Instituto de Engenharia de Produção e Gestão at Federal University of Itajubá, in Brazil. He holds the degrees of Mechanical Engineer from Federal University of Itajubá and M.S. in Mechanical Engineer from Federal University of Santa Catarina, and Doctorate of Engineering from Polytechnic School of University of São Paulo. His research interest includes Operational Research, Simulation and Economic Engineering. His e-mail address is <montevechi@unifei.edu.br>.

RENALDO GONZAGA DE ALMEIDA FILHO works at a Brazilian material defense manufacturing. He holds the degrees of Mechanical Engineer from Instituto Militar de Engenharia and M.S. in Operations Management from Federal University of Itajubá. His research interest include Operational Research, Simulation, Design of Experiments and Economic Engineering. His e-mail address is <renaldof@hotmail.com>.

ANDRÉ LUIZ MEDEIROS is a Substitute Professor of Instituto de Engenharia de Produção e Gestão at Federal University of Itajubá, in Brazil. He holds the degrees of Business Administrator from Federal University of Lavras and M.S. in Operations Management from Federal University of Itajubá. His research interest include Statistics, Regression Models and Economic Engineering. His e-mail address is <ecolimp. andre@terra.com.br>. 